\title{
Suicidal Ideation in Adolescence: Examining the Role of Recent Adverse Experiences
}

\author{
Richard Thompson, Ph.D., \\ Juvenile Protective Association \\ Laura J. Proctor, Ph.D., \\ San Diego State University \\ Diana J. English, Ph.D., \\ University of Washington \\ Howard Dubowitz, M.D., M.A., \\ University of Maryland \\ Subasri Narasimhan, Ph.D., and \\ University of North Carolina-Chapel Hill \\ Mark D. Everson, Ph.D. \\ University of North Carolina-Chapel Hill
}

\begin{abstract}
Although there is a well-known link between adverse experiences and suicidal ideation, there has been little study of the effects of recent adverse experiences on suicidal ideation in teenagers. This study examined the association between recent adverse experiences and suicidal ideation in a sample of 740 at-risk 16-year-old youth in the LONGSCAN studies, as well as potential mediators. $8.9 \%$ of the youth reported suicidal ideation. Recent adverse experiences, as a class, were associated with suicidal ideation; both recent physical abuse and recent psychological maltreatment were uniquely associated with suicidal ideation. The links between recent adverse experiences and suicidal ideation were significantly mediated by psychological distress. There were also significant main effect associations between both internalizing behavioral problems and low positive achievement expectations and suicidal ideation. Recent adverse experiences are important in understanding suicidal ideation in high risk youth.
\end{abstract}

\section{Introduction}

Youth suicidality is a significant public health problem; suicide is the third leading cause of death in youth, accounting for $12 \%$ of all deaths of youth aged 15 to 24 (AAS, 2009). In the United States, a youth under 25 commits suicide every two hours (AAS, 2009). In the last decades, youth suicide has been recognized as a significant public health problem, and efforts have intensified to understand suicidal behavior, which exists on a continuum from suicidal ideation to completed suicide (USPHS, 1999; IOM, 2002). Suicidal ideation is defined by the Institute of Medicine (2002) as thoughts of harming or killing oneself. Not only does suicidal ideation increase a youth's risk of suicide attempts and of death by suicide

(C) 2011 The Association for Professionals in Services for Adolescents. Published by Elsevier Ltd. All rights reserved.

Publisher's Disclaimer: This is a PDF file of an unedited manuscript that has been accepted for publication. As a service to our customers we are providing this early version of the manuscript. The manuscript will undergo copyediting, typesetting, and review of the resulting proof before it is published in its final citable form. Please note that during the production process errors may be discovered which could affect the content, and all legal disclaimers that apply to the journal pertain. 
(ten Have et al., 2010), it is also an important marker for an array of significant mental health needs, sexual risk behavior, substance use, and delinquent behavior (Thompson et al., 2010). These outcomes of youth suicidal ideation can persist long into adulthood (Fergusson et al., 2005). Despite these needs, youth with suicidal ideation are especially unlikely to seek help (Husky et al., 2009) and their suicidal ideation is often not recognized by others in their lives (Thompson et al., 2006). It is important, therefore, to better understand the factors that indicate risk of suicidal ideation in youth.

There is some evidence that adverse experiences can predispose youth to risk for suicidal ideation. From a variety of theoretical perspectives, such experiences shape cognitive and affective styles that predispose youth to psychological dysfunction and subsequent suicidal ideation (Brodsky \& Stanley, 2008). Recent evidence suggests that family dysfunction may be an especially important form of adverse experience (Bruffaerts et al., 2010; Stein et al., 2010). Child maltreatment has a relatively strong link with suicidal ideation, for young children and teenagers (Thompson et al., 2005). There is also some evidence that exposure to witnessed violence is associated with suicidal ideation (Thompson et al., 2005). In terms of type of violence witnessed, there is limited evidence supporting the effects of both family (Fitzpatrick et al., 2008) and community (Lambert et al., 2008) violence on suicidal ideation, although this distinction is rarely studied. Finally, a recent study by Qin and colleagues (2009) found some evidence that frequent family moves indicated risk of attempted suicide, suggesting it may also be a risk factor for suicidal ideation.

Although there is much research linking adverse experiences and suicidality, it has been of limited utility in informing prevention efforts. First, individual forms of adverse experience, such as particular types of maltreatment, have rarely been studied. For example, physical abuse (Bensley et al., 1999; Enns et al., 2006; Evans et al., 2005; Thompson et al., 2005) and sexual abuse (Bensley et al., 1999; Evans et al., 2005; Fergusson et al., 2000; Hardt et al., 2008) have been amply supported as predictors of suicidality, but less is known about neglect and psychological maltreatment; limited evidence suggests that these common forms of maltreatment may also be important predictors (Enns et al., 2006; Dube et al., 2001). Psychological maltreatment is defined by the American Academy of Pediatrics as a repeated pattern of damaging interactions between caregiver and child, and has been shown to have a host of negative consequences in other areas of mental health (Kairys, Johnson, \& Committee on Child Abuse and Neglect, 2002). Second, when particular adverse experiences have been examined individually, they have frequently been studied in isolation from other risk factors, or else simply included as cumulative indicators of risk. These approaches make it difficult to ascertain which factors in particular are likely to increase risk in real-world situations, where varying combinations of adverse experiences are common. Third, because much of the research on the influence of multiple childhood adversities has been conducted with adults retrospectively, little is known about the mechanisms by which adverse experiences increase risk for suicidal ideation (Brodsky \& Stanley, 2008). In other words, there has been very limited effort to understand which intervening variables may mediate the influence of adverse experiences such as maltreatment and witnessed violence on suicidal ideation.

What variables might mediate the link between adverse experiences and youth suicidality? In this research, two classes of potential mediators are considered: psychosocial functioning and future orientation. First, there is a great deal of circumstantial evidence to support the possibility that psychosocial functioning (broadly defined as psychological distress and behavioral problems) underlies the links between adverse experience and suicidality. Various indices of psychosocial functioning, chiefly depressive symptoms, psychological distress, and behavioral problems have been linked both with suicidal ideation (Fergusson et al., 2003; Fitzpatrick et al., 2008; Verona et al., 2004) and with exposure to adverse 
experiences (Briggs et al., in press; English et al., 2009). As well, there is some evidence that psychosocial functioning mediates the effects of particular adverse experiences on suicidal ideation; specifically, this relationship has been found for the effects of community violence (Lambert et al., 2008) and sexual abuse (Martin et al., 2004).

Recently, future orientation (broadly defined as expectations about the future and risk-taking behavior) has been proposed as a possible mediator of the link between adverse experiences and suicidal ideation (Evans et al., 2005; Stanton et al., 2003). Both impulsive and risktaking behavior, and negative expectations about the future are associated with both suicidal ideation (Borowski et al., 2009; Bossarte et al., 2008; Turecki, 2005; Valadez-Miller et al., 2005) and with exposure to adverse experiences (Black et al., 2009; Jones et al., 2010; Thompson et al., in press). There is limited research examining the mediating role of future expectations and risk taking on the link between adverse experiences and suicidal ideation, although some research has suggested that risk behavior like substance use may play such a role (Thompson et al., 2005).

The current analyses examine two questions: 1 ) the extent to which recent adverse experiences (exposure to various forms of maltreatment, witnessed violence, and residential instability), individually and as a group, are associated with suicidal ideation in a sample of high-risk 16-year-olds; and 2) the extent to which psychosocial functioning and future/risk orientation mediate the link between adverse experiences and suicidal ideation.

\section{Methods}

\section{Sample and Design}

LONGSCAN is a consortium of studies using common instruments and interview protocols, located at five sites in different regions of the United States: the Southern, Eastern, Midwest, Northwest, and Southwest. The current analyses use pooled data collected in these studies. Each site recruited a sample of children who were at risk of maltreatment or had been maltreated by the time they were four to six years old. The five sites differed in terms of recruitment criteria: one site included children that were at high risk for maltreatment, as defined by attendance of pediatric clinics serving children with non-organic failure to thrive, and children of drug-abusing or HIV-positive mothers (Eastern site), two sites included children who had been reported for maltreatment (Northwestern and Southwestern sites), and two sites included both children who had been reported as maltreated and children who were identified as at risk, based on mother age and community and family poverty (Southern and Midwestern site). Detailed information about recruitment strategies and the methods employed by LONGSCAN are available in Runyan et al. (1998).

Data collection consisted of interviews with target children and their primary caregivers, as well as of ongoing review of Child Protective Services (CPS) records. By design, interviews with varying levels of complexity were conducted with families every two years, keyed to the age of the target child (i.e., at ages 4, 6, 8, 10, 12, 14, and 16, with data collection at age 18 ongoing). Informed consent was obtained from caregivers and assent from child participants at each interview. Child and caregiver participants were interviewed separately. The current analyses focus primarily on data collected at ages 14 and 16, although some data from interviews at ages 8 and 12 were also used. These LONGSCAN interviews are described extensively on the LONGSCAN website (Knight, Smith, Martin, Lewis, \& the LONGSCAN Investigators, 2008; Knight, Smith, Martin, \& the LONGSCAN Investigators, 2009).

All participants with complete data on the outcome variable (suicidal ideation) assessed at age 16 were included in the present analyses. Of the 1354 child-caregiver dyads enrolled at 
baseline, 740 (54.7\%) youth completed the question on suicidal ideation at age 16. Those who participated at age 16 were compared with those without age 16 data, on baseline demographics and CBCL scores; there were no significant differences between the groups. The description of the analysis sample is included in Table 1. Correlations among recent adversities and potential mediators are presented in Table 2.

\section{Measures}

Suicidal Ideation (age 16)—At age 16, suicidal ideation was assessed using an item used to define suicidal ideation in the national Youth Risk Behavior Surveillance System, conducted by the Centers for Disease Control (Brener, Kann, Kinchen, et al., 2004). This item asked "During the last 12 months, did you ever seriously consider attempting suicide?" This item has substantial test-retest reliability (0.74), across a two week interval (Brener, Kann, McManus, Kinchen, Sundberg, \& Ross, 2002). For these analyses, this item was dichotomized

\section{Recent Adversities}

Maltreatment: Exposure to various forms of maltreatment was measured in two ways: administrative record review and self-report of the participating youth. Every two years, administrative records of Child Protective Services were searched to determine the presence and nature of allegations of maltreatment among participating youth. This review was done using the Modified Maltreatment Classification System (MMCS: English et al., 1997; a LONGSCAN-modified version of Barnett, Manly, \& Cicchetti, 1993). The coding procedures used in LONGSCAN for the MMCS are described in detail elsewhere (English, Bangdiwala, \& Runyan, 2005). Briefly, reviewers are trained on the classification system and required to achieve a $90 \%$ inter-rater reliability on practice case files prior to data collection. Five percent of the coded case narratives were reviewed by other LONGSCAN reviewers, to obtain inter-rater reliabilities. For the four classes of maltreatment examined here, kappas ranged from .73 for psychological maltreatment to .87 for physical abuse (English et al., 2005). The MMCS data collection included information on the date of the alleged maltreatment, the form which the alleged maltreatment took (physical abuse, sexual abuse, psychological maltreatment, or neglect), and other aspects of the alleged maltreatment. In these analyses, reports of maltreatment that occurred between the ages of 12 and 16 were included.

In addition to this administrative data collection, the participants were asked, as part of the age 16 interview, to report whether they had had a variety of experiences that could be construed as physical, sexual, or psychological abuse. The version of the measure administered at the age 16 interview is very similar to the measure administered at age 12 described in more detail elsewhere (Everson et al., 2008). The instrument was designed so that stem questions focusing on the timing of the event ("From the time you turned 12 up to now, has a parent or other adult who was supposed to be supervising you or taking care of you ever done something to you like..." with yes/no responses which would describe specific abuse experiences (e.g., "hit or punched you with their hand or fist, or kicked you?", "Touch or feel, or try to touch or feel, your private parts:?"). In each case (i.e., physical abuse, sexual abuse, and psychological abuse), a youth was coded as having reported such maltreatment if they endorsed any of these events over the time frame indicated. This instrument has modest but significant overlap with official reports of maltreatment (Everson et al., 2008), and very high internal consistency (ranging from 0.67 for physical abuse to 0.91 for sexual abuse) (Knight et al., 2009).

Following the recommendations of Everson and colleagues (2008), information from both self-report and administrative report on maltreatment was integrated. Youth were coded as 
having experienced a particular form of maltreatment if either self-report or administrative data indicated that such an experience had occurred. Because there was no self-report measure that mapped easily onto neglect, youth were coded as having experienced maltreatment based on administrative data only. All indicators of maltreatment were dichotomized for the analyses presented here.

Witnessed Violence: At age 16, youth reported on whether they had witnessed any of 7 forms of violence in the past year, ranging from relatively minor physical assault to severe forms of violence, including murder. Each positive endorsement of a witnessed event elicited follow-up questions that included who the victim(s) and perpetrator(s) were for each type of event endorsed (options included specific family members, friends, and strangers). There is some evidence for the validity of this measure; it correlates with caregiver reports of youth exposure to violence, as well as caregiver reports on community and family violence (Knight et al., 2009). For these analyses, the responses to this scale were dichotomized into two scales- children were categorized as to whether they had witnessed any form of violence that involved a non-family member either as a perpetrator or a victim, and whether they had witnessed any form of violence that involved a family member either as a perpetrator or a victim. This approach to scoring self-reported witnessed violence has been used in past analyses of the LONGSCAN data (e.g., Lewis et al., 2010; Thompson \& Whimper, 2010).

Instability (Residential Instability and Caregiver Instability)—Both residential and caregiver instability were defined using data collected using the Child's Life Events measure, a project modified measure designed to assess events occurring in a specific year of the youth's life (Hunter et al., 2003), based on Sarason's Life Experiences Survey (Sarason, Johnson, \& Siegel, 1978). Caregiver instability was conceptualized as change in caregiver arrangements, such caregivers' marriage, separation, divorce, moving out of the home, the addition of a significant other into the home, or death. Residential instability was conceptualized as instances where the child moved with the family to a new place, moved away from the family, spent time homeless or in a homeless shelter, the family was evicted, or the child stayed with friends or family because s/he had no place else to stay. These items correlated in predictable ways with other indicators of caregiver and residential stability and with child outcomes (English, Thompson, Graham, \& Briggs, 2005). For the present analyses, caregiver reports of caregiver instability and of residential instability were averaged across interviews collected at ages $13,14,15$, and 16 to obtain an index of the level of instability experienced between ages 12 and 16 .

\section{Possible Mediators: Psychosocial Functioning}

Psychological Distress: The Trauma Symptom Checklist for Children (TSCC; Briere, 1996), administered at age 16, was used to assess psychological distress. To produce an index of psychological distress, the items on this scale, excluding the two items which could be construed as indicating suicidal ideation, were summed. This index of psychological distress included symptoms of depressed mood, anger, anxiety, dissociation, and posttraumatic stress, experienced in the past two months. Cronbach alpha for this index of psychological distress in this sample was .84 .

\section{Externalizing and Internalizing Behavioral Problems-The Child Behavior}

Checklist (CBCL; Achenbach, 1991) was administered to assess caregiver ratings of youth behavior problems in two over-arching domains: internalizing problems and externalizing problems. Internalizing problems included items assessing anxiety/depression, somatic complaints, and social withdrawal. Externalizing problems included items assessing aggressiveness and delinquency. The CBCL is one of the most widely used and extensively 
validated caregiver reports of youth behavior problems (Achenbach \& Rescorla, 2001). Cronbach alphas for internalizing and externalizing in this sample were .88 for internalizing behavioral problems and .94 for externalizing problems.

\section{Possible Mediators: Risk/Future Orientation}

Risky Behavior: An index of risky behavior was derived from several LONGSCANdeveloped measures administered at age 16. From these interviews, the youth reported the degree of their involvement with the following risky behaviors in the previous year: delinquent/violent behavior (such as taking part in gang activities, being arrested, physically assaulting someone), smoking, alcohol use, use of illegal drugs, and having sex without using a condom. The ratings of frequency for each of these activities were summed to produce an overall indicator of the degree to which the youth engaged in risky behavior. Self-report measures of delinquent or violent behavior is usually regarded as valid (Cashel, 2003), as are the measures of substance use and sexually risky behavior to a lesser degree (Williams \& Nowatzki, 2005). The private nature of the assessment and the lack of consequences for affirmative responses to these questions was likely to increase the validity, and previous analyses using these questions from this sample has yielded evidence for the validity of this measure of risky behavior (Thompson et al., 2010).

Future Expectations-Future expectations were assessed at the age 16 interview through a series of project-developed questions around social and achievement outcomes. These questions asked youth to rate the likelihood of various outcomes on a 5-point Likert-like scale, ranging from "very unlikely" to "very likely." Similar questions had been asked at earlier interviews (e.g., Thompson \& Zuroff, 2010; Thompson et al., in press). Factor analyses revealed three domains of future expectations: positive achievement expectations (four items, e.g., "how likely are you to go to college?"), negative social expectations (three items, e.g., "how likely are you to have a child without being married?"), and positive social expectations (two items, e.g., how likely are you to get married?"). Cronbach alphas for these three scales range from .72 for negative social expectations to .85 for positive achievement expectations.

\section{Control Variables}

Demographics: The caregiver interview at each age included information on child gender, child race, caregiver education level, and family composition. For the purposes of analyses, child race was summarized into three categories: White, African American, and other. Caregiver education was measured in terms of the number of years of education. Family composition was also summarized using a dichotomous score based on whether children lived with their biological mothers. In most cases, when children were not living with their biological mothers, it was because they were in kinship foster care, or, less commonly were in non-kinship care. For these analyses, the demographic data collected at age 16 were used in the present study.

Lifetime Indicators of Suicidal Ideation-To take into account prior suicidal ideation, two items from the TSCC (Briere, 1996) administered at ages 8 and 12 which could be construed as indicative of suicidal ideation were combined. In particular, the two items from the TSCC that were used were "wanting to kill myself," and "wanting to hurt myself." Although they are somewhat more inclusive than the CDC definition, they have been used in previous research to define suicidal ideation, particularly with younger children (e.g., Thompson et al., 2005)

Lifetime Indicators of Distress: The TSCC (Briere, 1996) administered when children were aged 8 and age 12 was also used to create an index of lifetime psychological distress. 
To do this, the items on this scale, excluding the two items indicating possible suicidal ideation as noted above, were summed. These items assess symptoms of depressed mood, anger, anxiety, dissociation, and post-traumatic stress.

\section{Analytic Strategy}

To determine whether various forms of adversity were associated with suicidal ideation, a multivariate logistic regression was conducted. Specifically, variables were entered into the multivariate regression in two stages. The first stage contained a block of control variables (youth gender, youth race, caregiver education level, the presence of biological mother in the home, study site, and psychological distress at ages 8 and 12). The second stage contained the primary adverse experience variables of interest (physical abuse, sexual abuse, psychological abuse, neglect, witnessed family violence, witnessed non-family violence, caregiver instability, and residential instability). This allowed the evaluation of the independent effects of these adversities after taking into account the effects of demographics and other control variables. The indicators of earlier psychological distress were included in the control variable block to account for the effects of a predisposition toward distress generally. In general, the results were similar when these control variables were excluded from the analyses, although the variance explained was reduced somewhat.

Further, follow-up analyses were conducted to examine the effects of two different sets of potential mediators: psychosocial functioning (including psychological distress, internalizing behavioral problems, and externalizing behavioral problems) and risk/future orientation (risk behaviors, positive achievement expectations, negative social expectations, and positive social expectations). To examine this question, the bootstrapping method recommended by Preacher and Hayes (2008) was used; as well, these analyses were conducted using the SPSS macro described by Preacher and Hayes (2008). This approach allows a direct testing of mediation effects in the presence of a binary outcome, binary predictors, and in the presence of multiple potential mediators. In each case where an adverse experience was significantly associated with the outcome in the main effects analyses, a bootstrapping model was created with this variable as the predictor, all other control variables and adverse experience variables as control variables, and suicidal ideation as the outcome, as well as all 7 potential mediators entered simultaneously. This allowed a multivariate estimation of the direct and indirect effects of the predictor and potential mediator variables. In all cases, the indirect effects reported include bias-corrected $95 \%$ confidence intervals.

\section{Results}

\section{The Association between Adverse Experiences and Suicidal Ideation}

As noted on Table 1, the prevalence of suicidal ideation in this sample was $8.9 \%$. To test the effects of adverse experiences on risk of suicidal ideation, a multivariate logistic regression analysis was conducted. The results of this analysis are presented in Table 3. As shown, several control variables were associated with suicidal ideation: female gender, white (vs. African American) ethnic background, Southwest (vs. Northwest) site, and psychological distress at both ages 8 and 12 .

The overall block of adverse experiences was significantly associated with suicidal ideation and explained an additional $14.9 \%$ of the variance, over the effects of the control variables. Two adverse experiences had a significant and independent relationship to suicidal ideation: physical abuse, and psychological abuse. After controlling for a host of other risk factors, physical abuse was associated with a more than doubled likelihood of suicidal ideation and psychological abuse was associated with more than a tripled likelihood of suicidal ideation. 


\section{Potential Mediators of the Link between Physical Abuse and Suicidal Ideation}

As described earlier, a multiple mediator analysis (Preacher \& Hayes, 2008) was conducted to examine the degree to which each of the seven potential mediators (three indicating psychosocial functioning and four indicating risk/future orientation) mediated the link between physical abuse and suicidal ideation. These results are presented graphically in Figure 1. As can be seen, there were significant main effects relationships between physical abuse and following potential mediators: psychological distress, externalizing behavioral problems, positive achievement expectations, and negative social expectations. There were also significant main effects relationships between the following potential mediators and suicidal ideation: psychological distress, internalizing behavioral problems, and positive achievement expectations. Among the potential mediators, only psychological distress bore a significant indirect effect for the relationship between physical abuse and suicidal ideation (estimated effect $=0.52$, bias-corrected $\mathrm{CI}=0.02-0.77$, se $=0.24$ ). ${ }^{1}$

\section{Potential Mediators of the Link between Psychological Abuse and Suicidal Ideation}

As described earlier, a multiple mediator analysis (Preacher \& Hayes, 2008) was conducted to examine the degree to which each of the seven potential mediators (three indicating psychosocial functioning and four indicating risk/future orientation) mediated the link between psychological abuse and suicidal ideation. These results are presented graphically in Figure 2. As can be seen, there were significant main effects relationships between psychological abuse and following potential mediators: psychological distress and risky behavior. As noted earlier, there were also significant main effects relationships between the following potential mediators and suicidal ideation: psychological distress, internalizing behavioral problems, and positive achievement expectations. Among the potential mediators, only psychological distress bore a significant indirect effect for the relationship between physical abuse and suicidal ideation (estimated effect $=0.85$, bias-corrected $\mathrm{CI}=$ $0.30-0.97$, se $=0.26$ ).

\section{Discussion}

A central purpose of the analyses presented here was to examine the role of recent adverse experiences in understanding suicidal ideation in high risk youth. In our sample, there was a strong association with suicidal ideation for adverse experiences as a whole, and, among adverse experiences, physical abuse and psychological maltreatment. A second purpose was to examine whether psychosocial functioning and future/risk orientation mediated this link between adverse experiences and suicidal ideation. There was strong evidence that one indicator of psychosocial functioning (namely psychological distress) mediated this link, for both physical abuse and psychological abuse. Although other potential mediators (specifically, internalizing behavioral problems and low positive achievement expectations) were significantly associated with suicidal ideation, there was no evidence that they mediated the association between adverse experiences and suicidal ideation.

The finding that recent adverse experiences, especially indicators of family dysfunction, are associated with suicidal ideation is consistent with a growing body of research finding similar effects of earlier exposure to such adverse experiences in younger children and in adults (e.g., Felitti et al., 1998; Stein et al., 2010; Thompson et al., 2005). In particular, physical abuse had a unique effect on risk of suicidal ideation, consistent with previous research (Bensley et al., 1999; Brent et al., 2009; Evans et al., 2005). The unique effects of

\footnotetext{
${ }^{1}$ Estimated indirect effects estimated are reported only for the indirect effects found to be significant; all other indirect effects estimates are available from the first author.
} 
psychological maltreatment on suicidal ideation have been less frequently examined and should be a focus of future research.

Unlike some previous research (Bensley et al., 1999; Evans et al., 2005), there was no unique effect of sexual abuse. This may be because the relatively low rate of sexual abuse in the current sample limited the power to detect effects, or because the effects of sexual abuse are subsumed within the effects of adverse experiences more generally. There was also no evidence of a unique effect of either witnessed violence or of caregiver or residential instability, both of which have had tentative support in previous research (e.g., Qin et al., 2009; Stein et al., 2010; Thompson et al., 2005). However, as noted by Lambert and colleagues (2008), the effects of witnessed violence on suicidal ideation may be relatively modest after taking into account potential confounds. In particular, given the very high degree to which witnessed violence and child maltreatment co-occur (Finkelhor, Turner, Ormrod, \& Hamby, 2009), it may be difficult to disentangle these effects on child functioning.

The analyses also demonstrated a significant indirect effect through the mediator psychological distress. This is consistent with suggestions from earlier research that psychological functioning is a key mediator of the effects of particular adverse experiences on suicidal behavior (Breton et al., 2002; Evans et al., 2005; Fergusson et al., 2000). It is inconsistent, however, with previous research that failed to find such an indirect or mediating effect (e.g., Greening et al., 2008). There has also been some suggestion that externalizing behavior problems have unique predictive value (McGirr et al., 2008; Verona et al., 2004), but much of this latter research has focused on suicide attempts, rather than suicidal ideation, as an outcome.

The analyses also demonstrated that one indicator of future/risk orientation (specifically low positive expectations) was significantly associated with suicidal ideation, but failed to mediate the association between either physical abuse or psychological abuse and suicidal ideation. That low positive expectations were associated with suicidal ideation is consistent with previous work highlighting hopelessness as a key variable (Beautrais et al., 1999; Brent et al, 2009; Shahar et al., 2006). There was not, however, a significant link between risky behavior and suicidal ideation; this is contrary to most recent research which has found a significant effect on suicidal behavior (Affifi et al., 2007; Cho et al., 2007; Epstein \& Spirito, 2009). Two possible explanations for this discrepancy suggest themselves: 1) most previous work finding an effect of risk-taking behavior do not take into account beliefs about the future; and 2) the strongest effects of risk behavior are on suicide attempts rather than suicidal ideation (Cho et al., 2007; King et al., 2001).

In interpreting these results, it is important to keep in mind several limitations and methodological foci of the data used in the analyses. First, it is important to acknowledge that youth were oversampled for early reports of maltreatment. Thus, this was a relatively high-risk sample, and had very high base rates of the adverse experiences examined. The relatively high base rates of maltreatment were also influenced by the decision to include self-reports of maltreatment, as well as official reports. The inclusion of self-reports of maltreatment likely provide more valid indicators of youth experiences, especially in adolescence when child protective vigilance around maltreatment is typically lower (Everson et al., 2008), but may make the findings less comparable to other studies which relied solely on official reports of maltreatment. This also allowed more power to detect the effects of these experiences than may be present in other data. As well, the sample was predominantly low-income and nonwhite; these results should not be assumed to generalize to youth as a whole. As implied earlier, the outcome of focus here was suicidal ideation; suicide attempts and suicides may have had different associations. Although suicidal 
ideation, suicide attempts, and suicides have some common correlates, there are also important discontinuities among them (Silverman, Berman, Sanddal, O'Carroll, \& Joiner, 2007; Yoder, 1999). As well, more comprehensive and nuanced assessments of suicidal ideation are available, and the use of these might further add power to detect effects (Muehlenkamp, Cowles, \& Gutierrez, 2010). The predictive utility of the recent adverse experiences was relatively modest (uniquely explaining approximately $15 \%$ of the variance in suicidal ideation). This is comparable to other research examining potential predictors of suicidal ideation and highlights the modest degree to which suicidal ideation can be predicted by such variables (Thompson et al., 2005). Finally, the use of a multiple mediator model (Preacher \& Hayes, 2008) allowed the examination of multiple mediators simultaneously, an improvement over previous research; however, this approach is more conservative than other analyses, which often examined individual potential mediators in isolation.

It is also important to acknowledge some overlap in the timing of suicidal ideation, as assessed (i.e., within the last 12 months) and the adverse experiences examined (i.e., within the last 4 years). It is certainly true that the findings are consistent with conventional models wherein family dysfunction and adversity lead to impaired psychological functioning (though impairments in affect management, cognitive biases, and other means), which in turn leads to increased risk of suicidal ideation (Brodsky \& Stanley, 2008). However, the overlap in the time periods assessed makes it impossible to rule out alternative causal pathways. For example, it is known that poor psychological functioning in general is associated with increased risk of adverse experiences (Coyne, 1976; Shahar, Joiner, Zuroff, \& Blatt, 2004).

Another conceptual/assessment issue was with the focus on particular adverse experiences. Another approach might have been to examine the cumulative effect of adverse experiences, as has been done in other research (Dube et al., 2001). It is also important, in interpreting the findings, to keep in mind that the coefficients reported are the unique effects of particular variables, after taking all other variables into account. Thus, failure to find unique effects of particular variables should not be interpreted as evidence that there is no link between the variable and suicidal ideation. The adverse experiences examined tend to covary strongly, as did the potential mediators. For example, much previous research has established a strong association between family violence and psychological maltreatment, both empirical and conceptual (Baker, 2009; Casanueva, Martin, \& Runyan, 2009). As well, the current research focused on recent exposure to adverse experiences, rather than lifetime exposure. Finally, there are a host of other possible variables beyond the scope of the current analyses, which may also be important in understanding suicidal ideation: social support (Winfree \& Jiang, 2010), family warmth (Greening et al., 2010), parenting style (Connor \& Rueter, 2006), community level resources (Kubrin et al., 2006), and personality factors like conscientiousness (Nrugham et al., 2010).

These factors aside, the current findings highlight the importance of recent adverse experiences, particularly physical and psychological abuse, in the development of suicidal ideation. Psychological distress appears to be a key mediator of this link. Expectations about the future and internalizing behavioral problems were also significantly associated with suicidal ideation. Clinical interventions with youth experiencing suicidal ideation would benefit from focusing on alleviating psychological distress, internalizing psychological symptoms, and pessimism about the future. As well, although elevated psychological distress is a common problem, for a subset of youth it may indicate more profound psychosocial needs (Thompson et al., 2010). In addition to the other benefits of reducing child maltreatment in adolescence, doing so would also appear to have substantial benefits for youth mental health in general, and in reducing suicidal ideation in particular. 
Maltreatment of adolescent youth is often ignored by child protective services, and is rarely studied systematically, and this is especially true of psychological maltreatment (Everson et al., 2008). However, these results suggest that a subset of youth with such experiences experience suicidal ideation, indicating relatively profound, and usually unmet (Thompson et al., 2006), mental health needs.

\section{Acknowledgments}

This research was supported by grants to the Consortium for Longitudinal Studies on Child Abuse and Neglect (LONGSCAN) from the Children's Bureau, Office on Child Abuse and Neglect, Administration for Children, Youth, and Families.

\section{References}

Afifi TO, Cox BJ, Katz LY. The associations between health risk behaviours and suicidal ideation and attempts in a nationally representative sample of young adolescents. Canadian Journal of Psychiatry. 2007; 52:666-674.

American Association of Suicidology. 2009. Available online (accessed June 16, 2010): http:// www.suicidology.org/c/document_library/get_file?folderId=232\&name=DLFE-161.pdf

Baker AJL. Adult recall of childhood psychological maltreatment: Definitional strategies and challenges. Children and Youth Services Review. 2009; 31:703-714.

Beautrais AL, Joyce PR, Mulder RT. Personality traits and cognitive styles as risk factors for serious suicide attempts among young people. Suicide and Life-Threatening Behaviors. 1999; 29:37-47.

Bensley LS, Van Eenwyk J, Spieker SJ, Schoder J. Self-reported abuse history and adolescent problem behavior: I. Antisocial and suicidal behaviors. Journal of Adolescent Health. 1999; 24:163-172. [PubMed: 10195799]

Black MM, Oberlander SE, Lewis T, Knight ED, Zolotor AJ, Litrownik AJ, Thompson R, Dubowitz $\mathrm{H}$, English DE. Sexual intercourse among adolescents maltreated before age 12: A prospective investigation. Pediatrics. 2009; 124:941-949. [PubMed: 19706574]

Borowsky IW, Ireland M, Resnick MD. Health status and behavioral outcomes for youth who anticipate a high likelihood of early death. Pediatrics. 2009; 124:e81-e88. [PubMed: 19564273]

Bossarte RM, Simon TR, Swahn MH. Clustering of adolescent dating violence, peer violence, and suicidal behavior. Journal of Interpersonal Violence. 2008; 23:815-833. [PubMed: 18252941]

Brener ND, Kann L, Kinchen S, Grunbaum JA, Whalen L, Eaton D, Hawkins J, Ross JG. Methodology of the Youth Risk Behavior Surveillance System. Morbidity and Mortality Weekly Report. 2004; 53 No RR-12.

Brener ND, Kann L, McManus TL, Kinchen S, Sundberg EC, Ross JG. Reliability of the 1999 Youth Risk Behavior Survey Questionnaire. Journal of Adolescent Health. 2002; 31:336-342. [PubMed: 12359379]

Brent DA, Greenhill LL, Compton S, Emslie G, Wells K, Walkup JT, Vitiello B, Bukstein O, Stanley B, Posner K, Kennard BD, Cwik MF, Wagner A, Coffey B, March JS, Riddle M, Goldstein T, Curry J, Barnett S, Capasso L, Zelazny J, Hughes J, Shen S, Gugga SS, Turner JB. The Treatment of Adolescent Suicide Attempters Study (TASA): Predictors of suicidal events in an open treatment trial. Journal of the American Academy of Child and Adolescent Psychiatry. 2009; 48:987-996. [PubMed: 19730274]

Breton JJ, Tousignant M, Bergeron L, Berthiaume C. Informant-specific correlates of suicidal behavior in a community sample of 12- to 14-year-olds. Journal of the American Academy of Child and Adolescent Psychiatry. 2002; 41:723-730. [PubMed: 12049447]

Briere, J. Trauma Symptom Checklist for Children: Professional Manual. Odessa, FL: Psychological Assessment Resources; 1996.

Briggs EC, Thompson R, Ostrowski S, Lekwauwa R. The psychological, health, behavioral and economic costs of child abuse and neglect. Chapter in Violence Against Women and Children: Consensus, Critical analyses and Emergent Priorities Volume 1: Mapping the Terrain. In press. 
Brodsky BS, Stanley B. Adverse childhood experiences and suicidal behavior. Psychiatric Clinics of North America. 2008; 31:223-235. [PubMed: 18439446]

Bruffaerts R, Demyttenaere K, Borges G, Haro JM, Chiu WT, Hwang I, Karam EG, Kessler RC, Sampson N, Alonso J, Andrade LH, Angermeyer M, Benjet C, Bromet E, de Girolamo G, de Graaf R, Florescu S, Gureje O, Horiguchi I, Hu C, Kovess V, Levinson D, Posada-Villa J, Sagar R, Scott K, Tsang A, Vassilev SM, Williams DR, Nock MN. Childhood adversities as risk factors for onset and persistence of suicidal behavior. British Journal of Psychiatry. 2010; 197:20-27. [PubMed: 20592429]

Casanueva C, Martin SL, Runyan DK. Repeated reports for child maltreatment among intimate partner violence victims: Findings from the National Survey of Child and Adolescent Well-Being. Child Abuse and Neglect. 2009; 33:84-93. [PubMed: 19285725]

Cho H, Hallfors DD, Iritani BJ. Early initiation of substance use and subsequent risk factors related to suicide among urban high school students. Addictive Behaviors. 2007; 32:1628-1639. [PubMed: 17210230]

Connor J, Rueter MA. Parent-child relationships as systems of support or risk for adolescent suicidality. Journal of Family Psychology. 2006; 20:143-155. [PubMed: 16569099]

Coyne JC. Depression and the response of others. Journal of Abnormal Psychology. 1976; 85:186193. [PubMed: 1254779]

Dube SR, Anda RF, Felitti VJ, Chapman DP, Williamson DF, Giles WH. Childhood abuse, household dysfunction, and the risk of attempted suicide throughout the life span: Findings from the Adverse Childhood Experiences Study. Journal of the American Medical Association. 2001; 286:30893096. [PubMed: 11754674]

English DJ, Bangdiwala SI, Runyan DK. The dimensions of maltreatment: Introduction. Child Abuse and Neglect. 2005; 29:441-460. [PubMed: 15970319]

English DJ, Graham JC, Newton RR, Lewis TL, Thompson R, Kotch JB, Weisbart C. At-risk and maltreated children exposed to intimate partner aggression/Violence: What the conflict looks like and its relationship to child outcomes. Child Maltreatment. 2009; 14:157-171. [PubMed: 18984806]

English DJ, Thompson R, Graham JC, Briggs EC. Toward a definition of neglect in young children. Child Maltreatment. 2005; 10:190-206. [PubMed: 15798012]

Enns MW, Cox BJ, Afifi TO, deGraaf R, tenHave M, Sareen J. Childhood adversities and risk for suicidal ideation and attempts: a longitudinal population-based study. Psychological Medicine. 2006; 36:1769-1778. [PubMed: 16999880]

Epstein JA, Spirito A. Risk factors for suicidality among a nationally representative sample of high school students. Suicide and Life-Threatening Behavior. 2009; 39:241-251. [PubMed: 19606917]

Evans E, Hawton K, Rodham K. Suicidal phenomena and abuse in adolescents: A review of epidemiological studies. Child Abuse and Neglect. 2005; 29:45-58. [PubMed: 15664425]

Everson M, Smith JB, Hussey J, Dubowitz H, Litrownik A, English D, Knight L, Runyan D. Concordance between adolescent reports of childhood abuse and Child Protective Service determinations in an at-risk sample of young adolescents. Child Maltreatment. 2008; 13:14-26. [PubMed: 18174345]

Felitti VJ, Anda RF, Nordenberg D, Williamson DF, Spitz AM, Edwards V, Koss MP, Marks JS. Relationship of childhood abuse and household dysfunction to many of the leading causes of death in adults. American Journal of Preventive Medicine. 1998; 14:245-258. [PubMed: 9635069]

Fergusson DM, Beautrais AL, Horwood LJ. Vulnerability and resiliency to suicidal behaviours in young people. Psychological Medicine. 2003; 33:61-73. [PubMed: 12537037]

Fergusson DM, Horwood LJ, Ridder EM, Beautrais AL. Suicidal behaviour in adolescence and subsequent mental health outcomes in young adulthood. Psychological Medicine. 2005; 35:983993. [PubMed: 16045065]

Fergusson DM, Woodward LJ, Horwood LJ. Risk factors and life processes associated with the onset of suicidal behavior during adolescence and early adulthood. Psychological Medicine. 2000; 30:23-39. [PubMed: 10722173]

Finkelhor D, Turner H, Ormrod R, Hamby SL. Violence, abuse, and crime exposure in a national sample of children and youth. Pediatrics. 2009; 124:1411-1423. [PubMed: 19805459] 
Fitzpatrick KM, Piko BF, Miller E. Suicide ideation and attempts among low-income African American adolescents. Suicide and Life-Threatening Behavior. 2008; 38:552-563. [PubMed: 19014307]

Greening L, Stoppelbein L, Fite P, Dhossche D, Erath S, Brown J, Cramer R, Young L. Pathways to suicidal behaviors in childhood. Suicide and Life-Threatening Behavior. 2008; 38:35-45. [PubMed: 18355107]

Greening L, Stoppelbein L, Luebbe A. The moderating effects of parenting styles on AfricanAmerican and Caucasian children's suicidal behaviors. Journal of Youth and Adolescence. 2010; 39:357-369. [PubMed: 19806443]

Hallfors DD, Waller MW, Ford CA, Halpern CT, Brodish PH, Iritani B. Adolescent depression and suicide risk - Association with sex and drug behavior. American Journal of Preventive Medicine. 2004; 27:224-231. [PubMed: 15450635]

Hardt J, Sidor A, Nickel R, Kappis B, Petrak P, Egle UT. Childhood adversities and suicide attempts: A retrospective study. Journal of Family Violence. 2008; 23:713-718.

Husky MM, McGuire L, Flynn L, Chrostowski C, Olfson M. Correlates of help-seeking behavior among at-risk adolescents. Child Psychiatry and Human Development. 2009; 40:15-24. [PubMed: 18581231]

Institute of Medicine. Reducing suicide: A national imperative. Washington, DC: The National Academies Press; 2002.

Ivanoff A, Jang SJ, Smyth NJ, Linehan MM. Fewer reasons for staying alive when you are thinking of killing yourself: The Brief Reasons for Living Inventory. Journal of Psychopathology and Behavioral Assessment. 1994; 16:1-13.

Jones DJ, Runyan DK, Lewis T, Litrownik AJ, Black MM, Wiley T, English DE, Proctor LJ, Jones BL, Nagin DS. Trajectories of childhood sexual abuse and early adolescent HIV/AIDS risk behaviors: The role of other maltreatment, witnessed violence, and child gender. Journal of Clinical Child and Adolescent Psychology. 2010; 39:667-680. [PubMed: 20706919]

Kairys SW, Johnson CF. Committee on Child Abuse Neglect. The psychological maltreatment of children: Technical report. Pediatrics. 2002; 109:e68. [PubMed: 11927741]

Kaplow JB, Widom CS. Age of onset of child maltreatment predicts long-term mental health outcomes. Journal of Abnormal Psychology. 2007; 116:176-187. [PubMed: 17324028]

King RA, Schwab-Stone M, Flisher AJ, Greenwald S, Kramer RA, Goodman SH, Lahey BB, Shaffer D, Gould MS. Psychosocial and risk behavior correlates of youth suicide attempts and suicidal ideation. Journal of the American Academy of Child and Adolescent Psychiatry. 2001; 40:837846. [PubMed: 11437023]

Knight, ED.; Smith, JB.; Martin, LM.; Lewis, T. the LONGSCAN Investigators. Measures for Assessment of Functioning and Outcomes in Longitudinal Research on Child Abuse Volume 3: Early Adolescence (Ages 12-14). 2008. Accessible at the LONGSCAN web site (http:// www.iprc.unc.edu/longscan/)

Knight, ED.; Smith, JB.; Martin, LM. the LONGSCAN Investigators. Measures for Assessment of Functioning and Outcomes in Longitudinal Research on Child Abuse and Neglect Volume 4: Middle Adolescence (Age 16). 2009. Accessible at the LONGSCAN web site (http:// www.iprc.unc.edu/longscan/)

Klomek AB, Sourander A, Niemela S, Kumpulainen K, Piha J, Tamminen T, Almqvist F, Gould MS. Childhood bullying behaviors as a risk for suicide attempts and completed suicides: A populationbased birth cohort study. Journal of the American Academy of Child and Adolescent Psychiatry. 2009; 48:254-261. [PubMed: 19169159]

Kubrin CE, Wadsworth T, DiPietro S. Deindustrialization, disadvantage and suicide among young black males. Social Forces. 2006; 84:1559-1579.

Lambert SF, Copeland, Linder N, Ialongo NS. Longitudinal associations between community violence exposure and suicidality. Journal of Adolescent Health. 2008; 43:380-386. [PubMed: 18809136]

Martin G, Bergen HA, Richardson AS, Roeger L, Allison S. Sexual abuse and suicidality: Gender differences in a large community sample of adolescents. Child Abuse and Neglect. 2004; 28:491503. [PubMed: 15159067] 
McGirr A, Renaud J, Bureau A, Seguin M, Lesage A, Turecki G. Impulsive-aggressive behaviours and completed suicide across the life cycle: a predisposition for younger age of suicide. Psychological Medicine. 2008; 38:407-417. [PubMed: 17803833]

Muehlenkamp JJ, Cowles ML, Gutierrez PM. Validity of the Self-Harm Behavior Questionnaire with diverse adolescents. Journal of Psychopathology and Behavioral Assessment. 2010; 32:236-245.

Nrugham L, Holen A, Sund AM. Associations between attempted suicide, violent life events, depressive symptoms, and resilience in adolescents and young adults. Journal of Nervous and Mental Disease. 2010; 198:131-136. [PubMed: 20145488]

Qin P, Mortensen PB, Pedersen CB. Frequent change of residence and risk of attempted and completed suicide among children and adolescents. Archives of General Psychiatry. 2009; 66:628-632. [PubMed: 19487627]

Shahar G, Bareket L, Rudd MD, Joiner TE. In severely suicidal young adults, hopelessness, depressive symptoms, and suicidal ideation constitute a single syndrome. Psychological Medicine. 2004; 36:913-922. [PubMed: 16650341]

Shahar G, Joiner TE, Zuroff DC, Blatt SJ. Personality, interpersonal behavior, and depression: coexistence of stress-specific moderating and mediating effects. Personality and Individual Differences. 2004; 36:1583-1596.

Silverman MM, Berman AL, Sanddal ND, O'Carroll PW, Joiner TE. Rebuilding the tower of Babel: A revised nomenclature for the study of suicide and suicidal behaviors. Part 2: Suicide-related ideations, communications, and behaviors. Suicide and Life-Threatening Behavior. 2007; 37:264277. [PubMed: 17579539]

Stanton C, Spirito A, Donaldson D, Boergers J. Risk-taking behavior and adolescent suicide attempts. Suicide and Life-Threatening Behavior. 2003; 33:74-79. [PubMed: 12710542]

Stein DJ, Chiu WT, Hwang I, Kessler RC, Sampson N, Alonso J, Borges G, Bromet E, Bruffaerts R, de Girolamo G, Florescu Sl, Gureje O, he Y, Kovess-Masfety V, Levinson D, Matschinger H, Mneimneh Z, Nakamura Y, Ormel J, Posada-Villa J, Sagar R, Scott KM, Tomov T, Viana MC, Williams DR, Nock MK. Cross-national analysis of the associations between traumatic events and suicidal behavior: Findings from the WHO World Mental Health Surveys. PLoS One. 2010; 5:e10574. [PubMed: 20485530]

Swahn MH, Bossarte RM. Gender, early alcohol use, and suicide ideation and attempts: Findings from the 2005 youth risk behavior survey. Journal of Adolescent Health. 2007; 41:175-181. [PubMed: $17659222]$

ten Have M, de Graaf R, von Dorsselaer S, Verdurmen J, van't Land H, Vollebergh W, Beekman A. Incidence and course of suicidal ideation and suicide attempts in the general population. Canadian Journal of Psychiatry. 2010; 54:824-833.

Thompson MP, Ho CH, Kingree JB. Prospective associations between delinquency and suicidal behaviors in a nationally representative sample. Journal of Adolescent Health. 2007; 40:232-237. [PubMed: 17321423]

Thompson R, Briggs E, English DJ, Dubowitz H, Lee LC, Brody K, Everson MD, Hunter WM. Suicidal ideation among maltreated and at-risk 8-year-olds: Findings from the LONGSCAN studies. Child Maltreatment. 2005; 10:26-36. [PubMed: 15611324]

Thompson R, Dubowitz H, English DJ, Nooner KB, Wike T, Bangdiwala SI, Runyan DK, Briggs EC. Parents' and teachers' concordance with children's self-ratings of suicidality: Findings from a highrisk sample. Suicide and Life-Threatening Behavior. 2006; 36:167-181. [PubMed: 16704322]

Thompson R, Litrownik AJ, Weisbart C, Kotch JB, English DJ, Everson MD. Adolescent outcomes associated with early maltreatment and exposure to violence: The role of early suicidal ideation. International Journal of Child and Adolescent Health. 2010; 3:55-66.

Thornberry TP, et al. The causal impact of childhood-limited maltreatment and adolescent maltreatment on early adult adjustment. Journal of Adolescent Health. 2010; 46:359-365. [PubMed: 20307825]

Turecki G. Dissecting the suicide phenotype: the role of impulsive-aggressive behaviours. Journal of Psychiatry and Neuroscience. 2005; 30:398-408. [PubMed: 16327873]

US Public Health Service. The Surgeon General's Call to Action to Prevent Suicide. Washington, DC: Public Health Service; 1999. 
Valadez-Meltzer A, Silber TJ, Meltzer AA, D'Angelo LJ. Will I be alive in 2005? Adolescent level of involvement in risk behaviors and belief in near-future death. Pediatrics. 2005; 116:24-31. [PubMed: 15995026]

Verona E, Sachs-Ericsson N, Joiner TE. Suicide attempts associated with externalizing psychopathology in an epidemiological sample. American Journal of Psychiatry. 2004; 161:444451. [PubMed: 14992969]

Winfree LT, Jiang S. Youthful suicide and social support: Exploring the social dynamics of suiciderelated behavior and attitudes within a national sample of US adolescents. Youth Violence and Juvenile Justice. 2010; 8:19-37.

Yoder KA. Comparing suicide attempters, suicide ideators, and nonsuicidal homeless and runaway adolescents. Suicide and Life-Threatening Behavior. 1999; 29:25-36. [PubMed: 10322618] 


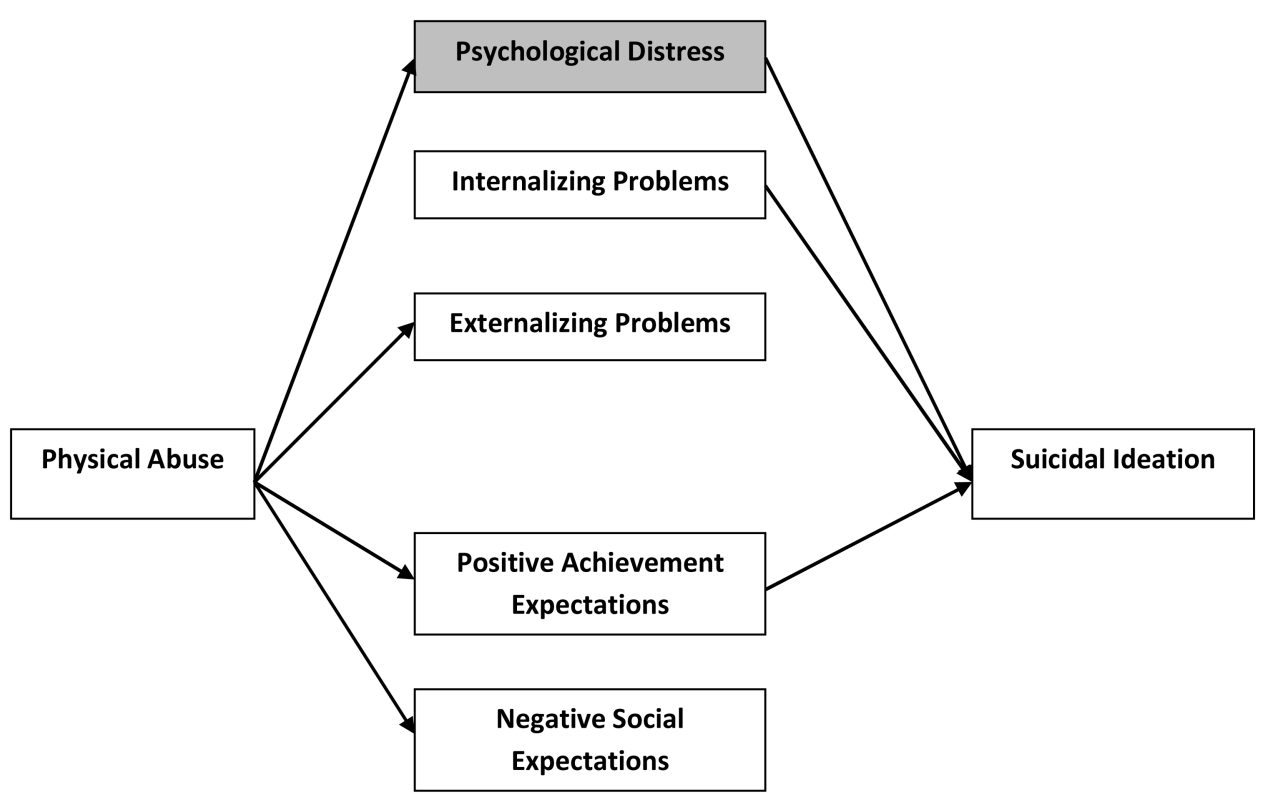

Figure 1. Links between Physical Abuse, Potential Mediatiors, and Suicidal Ideation NOTE: Lines represent significant relationships at $\mathrm{p}<.05$. Potential mediators carrying a significant indirect effect are indicated by grayscale shading. Positive Social Expectations and Risky Behavior excluded from this figure because they had no significant relationship with either physical abuse or with suicidal ideation 


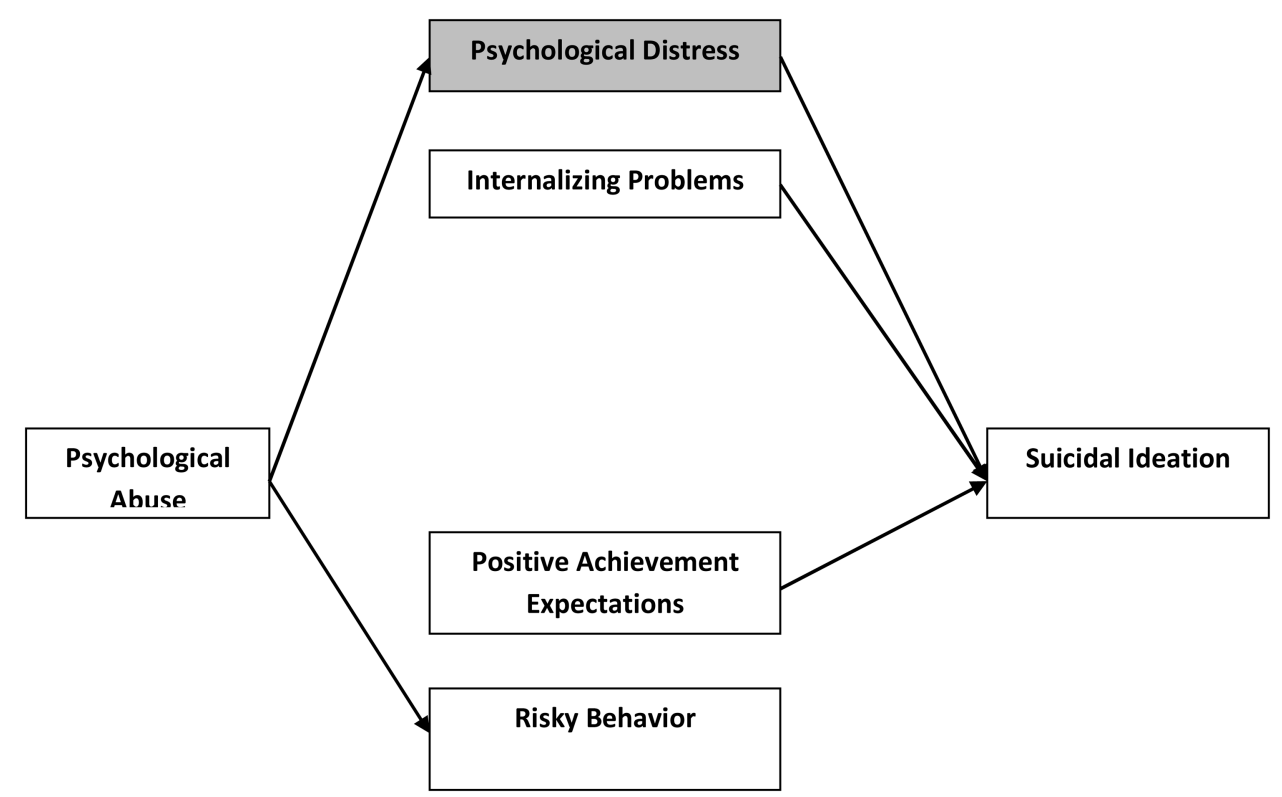

Figure 2. Links between Psychological Abuse, Potential Mediatiors, and Suicidal Ideation NOTE: Lines represent significant relationships at $\mathrm{p}<.05$. Potential mediators carrying a significant indirect effect are indicated by grayscale shading. Externalizing Behavioral Problems, Negative Social Expectations, and Positive Social Expectations excluded from this figure because they had no significant relationship with either psychological abuse or with suicidal ideation 
Table 1

Description of the sample $(N=740)$

\begin{tabular}{|c|c|}
\hline VARIABLE & M (SD) or \% (N) \\
\hline \multicolumn{2}{|l|}{ Outcome } \\
\hline Suicidal Ideation (Age 16) & $8.9 \%(66)$ \\
\hline \multicolumn{2}{|l|}{ Control Variables } \\
\hline \multicolumn{2}{|l|}{ Race } \\
\hline White & $25.4 \%(188)$ \\
\hline African American & $52.6 \%(389)$ \\
\hline Other & $22.0 \%(163)$ \\
\hline \multicolumn{2}{|l|}{ Gender } \\
\hline Female & $52.6 \%(389)$ \\
\hline Male & $47.4 \%(351)$ \\
\hline Caregiver Education & $12.30(2.19)$ \\
\hline Biological Mother in the Home (yes) & $59.5 \%(440)$ \\
\hline \multicolumn{2}{|l|}{ Site } \\
\hline Eastern & $19.9 \%(147)$ \\
\hline Southern & $15.0 \%(111)$ \\
\hline Midwestern & $16.5 \%(122)$ \\
\hline Northwestern & $24.6 \%(182)$ \\
\hline Southwestern & $24.1 \%(178)$ \\
\hline Psychological Distress (TSCC; age 8) & $30.90(19.21)$ \\
\hline Psychological Distress (TSCC; age 12) & $12.99(13.72)$ \\
\hline Prior possible suicidal ideation (TSCC; age 8 or 12) & $25.7 \%(190)$ \\
\hline \multicolumn{2}{|l|}{ Predictors } \\
\hline Physical Abuse & $25.5 \%(189)$ \\
\hline Sexual Abuse & $10.4 \%(77)$ \\
\hline Psychological Abuse & $34.9 \%(258)$ \\
\hline Neglect & $10.1 \%(75)$ \\
\hline Witnessed Violence (Family) & $0.55(1.48)$ \\
\hline Witnessed Violence (Non-Family) & $3.72(3.62)$ \\
\hline Instability (Caregiver) & $0.32(0.46)$ \\
\hline Instability (Residential) & $0.41(0.49)$ \\
\hline \multicolumn{2}{|l|}{ Mediators } \\
\hline Psychological Distress (TSC; age 16) & $16.11(14.25)$ \\
\hline Internalizing (CBCL) & $48.86(11.86)$ \\
\hline Externalizing (CBCL) & $53.29(11.93)$ \\
\hline Risk-Taking & $5.38(4.06)$ \\
\hline Future Expectations: Positive Achievement & $4.06(0.75)$ \\
\hline Future Expectations: Negative Social & $2.38(0.81)$ \\
\hline
\end{tabular}




\begin{tabular}{|l|r|}
\hline VARIABLE & M (SD) or \% (N) \\
\hline Future Expectations: Positive Social & $3.81(0.86)$ \\
\hline
\end{tabular}



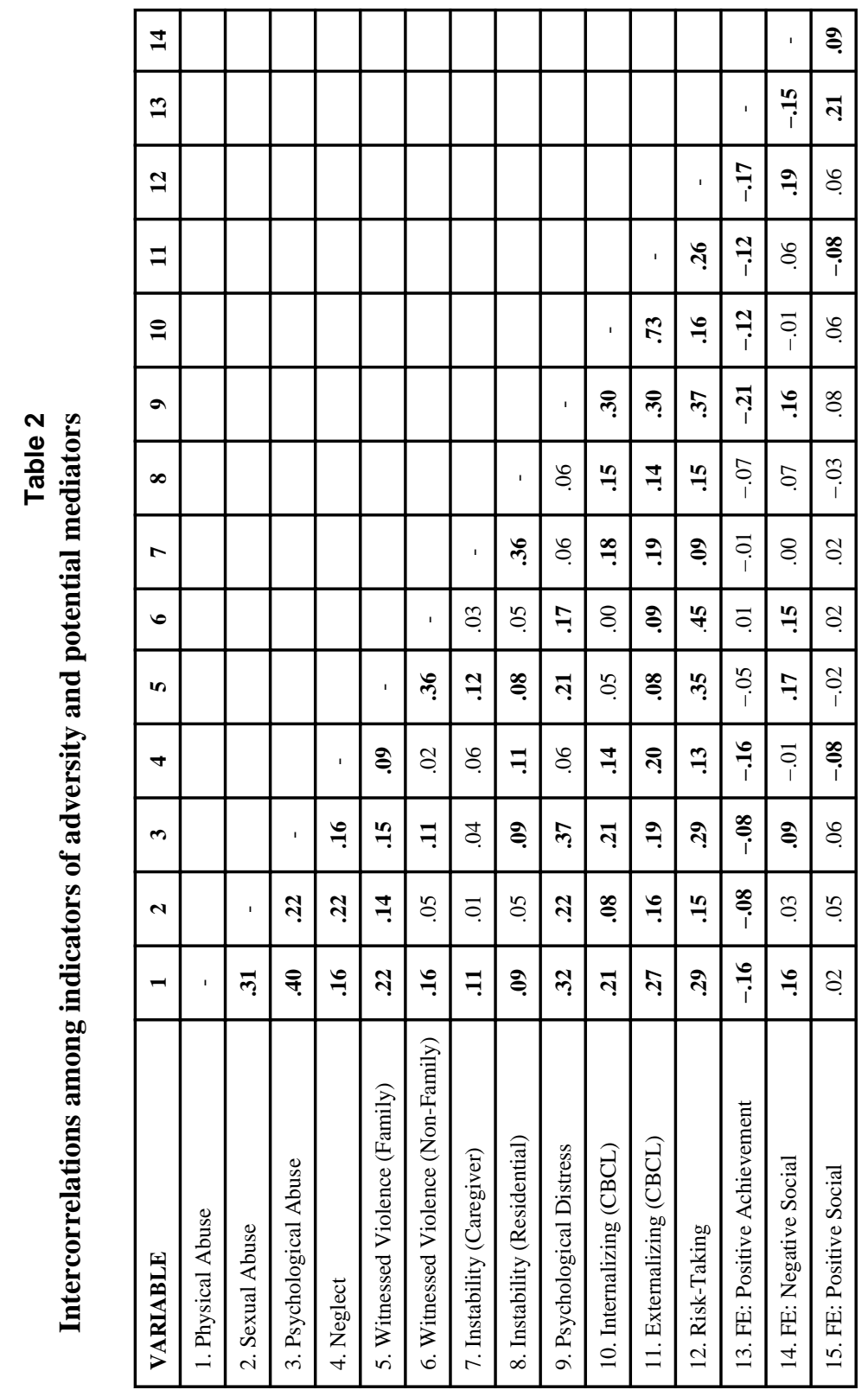
Table 3

Multivariate Logistic regression predicting suicidal ideation $(\mathrm{N}=\mathbf{7 4 0})$

\begin{tabular}{|c|c|}
\hline VARIABLES & OR $(\mathbf{C I})$ \\
\hline CONTROL & $X^{2}(12)=52.52 ; \Delta R^{2}=.186$ \\
\hline Gender (Male vs. Female) & $0.33(0.16-0.67)$ \\
\hline Race (REF: White) & 1.00 \\
\hline African American & $0.31(0.14-0.70)$ \\
\hline Other & $0.30(0.12-0.76)$ \\
\hline Caregiver Education (per year) & $0.99(0.85-1.15)$ \\
\hline Biological Mom in Home (Yes vs. No) & $1.44(0.68-3.05)$ \\
\hline Site (REF: NW) & 1.00 \\
\hline EA & $1.05(0.31-3.58)$ \\
\hline MW & $0.77(0.19-3.09)$ \\
\hline SO & $1.49(0.53-4.22)$ \\
\hline SW & $2.70(1.09-6.68)$ \\
\hline Distress (TSC-age 8) & $1.02(1.01-1.04)$ \\
\hline Distress (TSC-age 12) & $1.02(1.00-1.04)$ \\
\hline Possible suicidal ideation (TSC- 8 or 12) & $1.09(0.50-2.39)$ \\
\hline RECENT ADVERSITIES & $\mathrm{CHI}(8)=44.66 ; \Delta \mathrm{R}^{2}=.149$ \\
\hline Physical Abuse (any) & $2.60(1.28-5.30)$ \\
\hline Sexual Abuse (any) & $0.98(0.39-2.46)$ \\
\hline Psychological Abuse (any) & $3.66(1.80-7.44)$ \\
\hline Neglect (official) & $0.60(0.19-1.87)$ \\
\hline Witnessed Violence (family) & $1.05(0.85-1.30)$ \\
\hline Witnessed Violence (non-family) & $1.10(0.99-1.22)$ \\
\hline Instability (caregiver) & $0.84(0.41-1.73)$ \\
\hline Instability (residential) & $0.97(0.50-1.92)$ \\
\hline
\end{tabular}

